\title{
Comparison of Occurrence of Injuries to Footballers at Low and High Level of Achievement
}

Sinku, S. K.

Lecturer and Head, Department of Physical Education,

Shri Sant Sawata Mali Gramin Mahavidhyalaya, Phulambri, Aurangabad, Maharashtra.

\section{Abstract}

The primary aim of the investigation was to compare the occurrence of injuries to footballers at low and high level of achievement with regard to various stages viz. ground conditions, location, field positions, training and competition. Information on injuries was collected from members of eight Indian football teams which were participating in the All India Mayor Trophy football tournament by questionnaires. In all 98 injuries were observed, 40 related to the low achievement and 58 to the high achievement group of footballers. A significant difference in the occurrence of injuries between the two achievement groups of footballers was found. Occurrence of injuries due to field conditions and position of playing were also found to be significantly different in the two achievement groups. No significant differences in injury occurrence were found between group of footballers with respect to location. Significant difference in the occurrence of injuries were observed in the groups with respect to the frequency of competition and training periods $(\mathrm{t}=2.46, \mathrm{p}<.05)$ of footballers. While comparing causes and nature of injuries, no significant differences were found between the low and the high level of achievement footballers. The high level of achievement footballers revealed more injuries than the low level of achievement footballers. Those football players directly involved in attack or defence are more likely to be injured. Lower limb injuries were found to be predominant. The results of the study provide a useful insight into the injuries in relation to the field position, nature and location of injury in competitive football players.

\section{Keywords: Footballers, Injuries, Training, Achievement level}

\section{Introduction}

Football is one of the most popular sports in the world. Currently FIFA unified 203 National Associations and represents abouts 200 million active players, of which about 40 million are women. The incidence of football injuries is estimited to be $10-35$ per game hour. An athlete plays on average about 100 hours of football per year (ranging between 50 hours per player of a local team to upto 500 hours per player for a professional team).

Australian Football Association reported 4681 injuries between 1992 and 1998 (Orchard et al, 1997 \& 1998). In this report, it was reported that players from teams in Northem states were slightly more (14\%) likely to be injured than players from teams in Victoria (RR $1.14,95 \%$ CI $1.07-1.21)$. There was no significant difference in the risk for injury to upper limb, trunk or head and neck regions. However incidence of incurring injuries to the lower limb (ankle injuries, calf and quadriceps strain etc) was reported to be greater in players from Northen teams than the teams from Victoria.

Football has been demonstrated to be among the most hazardous of organized team sports and injury is a frequent event in football (Griffith, 1989; Saxby, 1989; Seward \& Patrik, 1992; Watson, 1993; Junge, 2004; Singh, 2004, 2006; Singh \& Pagare, 2007). Football 
requires a variety of physical attributes and specific playing skills therefore participants need to train and prepare to meet at least a minimum set of physical, physiological and psychological requirements to cope with the demands of the game and to reduce the risk of injury (Griffith, 1989). It is an enjoyable and social sport that can be played from childhood to old age, either at a recreational level or as a competitive sport.

Football playing largely involves accelerating, running, slopping, twisting, and turnning at various ranges of movement alongwith stretching, jumping and kicking action (Griffith, 1989; Pardon, 1997). All these factors place the players to a greater risk of injury. The aim of the present study is to campare the injuries in low and high level of achievement footballers.

\section{Material \& Methods}

The investigator has made an attempt to classify or define the level of footballers based on the class of the games of the footballers. Accordingly two groups of footballers were targeted; low and high level of achievement footballers aged between 16 to 30 years. The low level achievement footballers were those who were regularly participating for three years in the National football competitions and the high level of achievement footballers were regularly participating for three years in the International football tournaments.

Information on injuries was collected from eight Indian football teams, which were participating in the All India Mayor Trophy football tournament that was held in September 2006, in the city of Aurangabad, Maharashtra. A questionnaire prepared by Cromwell \& Gromely (2000) for elite Gaelic football players and modified by the investigator was used. T-ratio was computed to compare the occurrence of injuries between the low and the high level of achievement footballers. The investigator personally contacted the team managers and coaches of the eight teams and the purpose of the study was explained to them. Further instructions were given by the investigator to the players for the completion of the questionnaire.

\section{Results \& Discussion}

The mean $( \pm$ S.D. $)$ of the age of the low level achievement footballers was $19.66( \pm 1.33)$ years, height $167.33( \pm 8.33)$ $\mathrm{cm}$, weight $61.25( \pm 8.77) \mathrm{kg}$, training duration $1.66( \pm 0.42)$ hours and the competition frequency/year $6.74( \pm 2.33)$. On the other hand, the mean $( \pm$ S.D. $)$ of the age of the high level achievement footballers was $21.08( \pm 1.78)$ years, height $170.52( \pm 8.33) \mathrm{cm}$, weight $62.44( \pm 8.98)$ $\mathrm{kg}$., training duration $4.91( \pm 1.21)$ hours and the competion frequency/year $10.06( \pm 3.78)$. The statistics of the results of injuries in football players are shown in Tables 1 to 8 . With regard to the occurrence of incidence of injuries in the low and the high level of achievement footballers, mean values of 0.67 and 0.98 respectively were observed (Table-1). The obtained $\mathfrak{t}=2.58$ was significant at 0.05 level indicating that the high level of achievement footballers had greater incidence of injuries than the low achievement footballers.

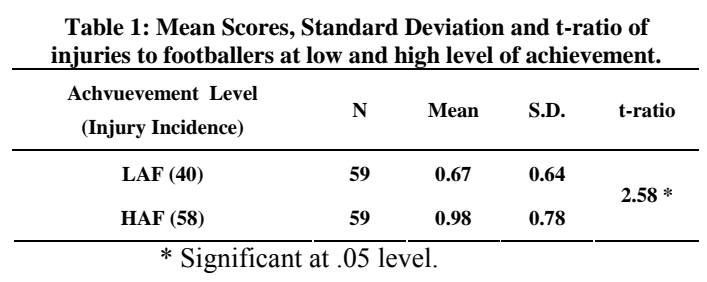


Table 2: Statistical information related to occurrence of injuries due to ground condition in low and high level of achievement footballers.

\begin{tabular}{|c|c|c|c|c|}
\hline $\begin{array}{l}\text { Achvuevement Level } \\
\text { (Injury Incidence) }\end{array}$ & $\mathbf{N}$ & Mean & S.D. & t-ratio \\
\hline LAF & 40 & 0.17 & 0.37 & \multirow{2}{*}{$3.11 * *$} \\
\hline HAF & 37 & 0.45 & 0.49 & \\
\hline
\end{tabular}

As per table 2, a significant injury differences were found out in the low and the high level achievement footballers $(\mathrm{t}=3.11, \mathrm{p}<.01)$.

High level achievement footballers demonstrate significantly greater incidence of occurrence of injuries due to ground conditions as compared to the low level achievement footballers.

\begin{tabular}{|c|c|c|c|c|c|}
\hline Field Position & $\begin{array}{c}\text { Achvuevement } \\
\text { Level (Injury } \\
\text { Incidence) }\end{array}$ & $\mathbf{N}$ & Mean & SD & t-ratios \\
\hline \multirow{2}{*}{ Center Forward } & LAF (3) & 2 & 1.5 & 0.25 & \multirow{2}{*}{$3.59 *$} \\
\hline & HAF (8) & 3 & 2.66 & 0.47 & \\
\hline \multirow{2}{*}{ Left Full back } & LAF (2) & 3 & 0.66 & 0.42 & \multirow{2}{*}{$2.38^{\mathrm{NS}}$} \\
\hline & HAF (7) & 5 & 1.4 & 0.6 & \\
\hline \multirow{2}{*}{ Left Halves back } & LAF (4) & 6 & 0.83 & 0.47 & \multirow{2}{*}{$3.89 * *$} \\
\hline & HAF (7) & 4 & 1.75 & 0.43 & \\
\hline \multirow{2}{*}{ Center Halves } & LAF (7) & 9 & 0.77 & 0.41 & \multirow{2}{*}{$3.04 * *$} \\
\hline & HAF (9) & 6 & 1.5 & 0.5 & \\
\hline \multirow{2}{*}{ Goal Keeper } & LAF (5) & 8 & 0.62 & 0.61 & \multirow{2}{*}{$2.07^{\mathrm{NS}}$} \\
\hline & HAF (14) & 12 & 1.66 & 0.54 & \\
\hline \multirow{2}{*}{ TOTAL } & LAF (21) & 28 & 0.75 & 0.43 & \multirow{2}{*}{$5.13 * * *$} \\
\hline & HAF (45) & 30 & 1.5 & 0.67 & \\
\hline
\end{tabular}

Table 3 shows, the means, SDs. and t-ratios of occurrence of injuries to the low and the high level of achievement footballers as well as combined sample for different field positions. Incidence of the occurrence of injuries is depicted for only five different field positions.

In case of inside left (forward) outside right (forward), right full back, outside left (forward) and non specific mid fielder no injury was reported in both the high and the low level of achievement footballers, hence, these field positions were not included.

Similarly in case of right halves back and inside right only low level achievement footballers reported injuries while none of the high level achievement footballers engaged in these field positions reported injuries, hence could not be included for comparison. Statistically significant differences in the occurrence of injuries were found in the high and the low achievement group of footballers with respect to center forward $(\mathrm{t}=3.59, \mathrm{P}<0.05)$, left halves back $(\mathrm{t}=3.89$, $\mathrm{P}<0.05$ ), center half playing position $(\mathrm{t}=3.04, \mathrm{P}<0.01)$, while in case of goal keepers $(\mathrm{t}=2.07)$, and left full back $(t=2.38)$ no significant differences were found.

Table 4 indicates the existence of statistically significant differences among the high and the low achievement footballers with respect to the location of occurrence of injuries. Significant differences were found in the occurrence of injuries with respect to ankle $(\mathrm{t}=3.53$, $\mathrm{P}<0.01)$, shoulder $(\mathrm{t}=5.5, \mathrm{P}<0.001)$, knee $(\mathrm{t}=2.37, \mathrm{P}<0.05)$ among the high and the low achievement footballers while differences in the occurrence of injury in hamastring region $(t=0.42)$ was found not significant.

In case of other regions like back, wrist and quadriceps; injuries were reported by LAF only, while HAF revealed injuries in the head, hip, hand, and groin regions, hence, these locations could not be included in this study for comparison. 
Table 4: Statistical information of incidence of injuries recorded in low and high level of achievement footballers with respect to location of injury.

\begin{tabular}{|c|c|c|c|c|c|}
\hline Location & $\begin{array}{c}\text { Achvuevement } \\
\text { Level (Injury } \\
\text { Incidence) }\end{array}$ & $\mathbf{N}$ & Mean & SD & t-ratios \\
\hline \multirow{2}{*}{ Ankle } & LAF (10) & 04 & 2.5 & 0.5 & \multirow{2}{*}{$3.53 * *$} \\
\hline & HAF (13) & 09 & 1.44 & 0.51 & \\
\hline \multirow{2}{*}{ Hamstring } & LAF (3) & 02 & 1.55 & 0.5 & \multirow{2}{*}{$0.42^{\mathrm{NS}}$} \\
\hline & HAF (5) & 04 & 1.25 & 0.83 & \\
\hline \multirow{2}{*}{ Shoulder } & LAF (11) & 10 & 1.1 & 0.3 & \multirow{2}{*}{$5.5 * * *$} \\
\hline & HAF (11) & 05 & 2.2 & 0.4 & \\
\hline \multirow{2}{*}{ Knee } & LAF (6) & 05 & 1.2 & 0.30 & \multirow{2}{*}{$2.37 *$} \\
\hline & HAF (16) & 09 & 1.77 & 0.62 & \\
\hline \multirow{2}{*}{ TOTAL } & LAF (30) & 15 & 2 & 0.58 & \multirow{2}{*}{$0.89^{\mathrm{NS}}$} \\
\hline & HAF (45) & 27 & 1.66 & 0.47 & \\
\hline
\end{tabular}

Table 5: Statistical information of incidence of injuries recorded in low and high level of achievement footballers during competition and training period.

\begin{tabular}{|c|c|c|c|c|c|c|}
\hline & \multicolumn{2}{|c|}{$\begin{array}{c}\text { Injury } \\
\text { Incidence } \\
\text { during } \\
\text { Competition }\end{array}$} & \multicolumn{2}{|c|}{$\begin{array}{c}\text { Injury } \\
\text { Incidence } \\
\text { during } \\
\text { Training } \\
\end{array}$} & \multicolumn{2}{|c|}{ Total } \\
\hline & LAF & HAF & LAF & HAF & Competition & Training \\
\hline $\mathbf{N}$ & 13 & 19 & 24 & 21 & 37 & 40 \\
\hline Means & 1.44 & 1.11 & 1.04 & 1.71 & 1.08 & 1.45 \\
\hline S.Ds. & 0.82 & 0.30 & 0.20 & 1.03 & 0.48 & 0.83 \\
\hline t-ratios & \multicolumn{2}{|c|}{$1.47 \mathrm{NS}$} & \multicolumn{2}{|c|}{$3.04 * *$} & \multicolumn{2}{|c|}{$2.46 *$} \\
\hline
\end{tabular}

Table 5 depicts the statistical information of incidence of injuries recorded in the low and the high level achievement footballers during competition and training period periods. Significant differences in the occurrence of injuries are found out in relation to both the competition and the training periods in the combined sample $(\mathrm{t}=2.46$, $\mathrm{p}<0.05$ ),

Low level achievement footballers incur significantly less number of injuries as compared to the high level of achievement footballers during the training period $(\mathrm{t}=3.04, \mathrm{p}<.01)$. Whilist no significant difference in the incidence of injuries were found between the low and the high level of achievement footballers during the competition period $(\mathrm{t}=1.47)$.
Table 6: Statistical comparison of incidence of injuries recorded in low and high level of achievement footballers with respect to Lower and Upper Limbs

\begin{tabular}{lcccccc}
\hline & \multicolumn{2}{c}{$\begin{array}{c}\text { Upper Limb } \\
\text { (UL). }\end{array}$} & \multicolumn{2}{c}{$\begin{array}{c}\text { Lower Limb } \\
\text { (LL) }\end{array}$} & \multicolumn{2}{c}{$\begin{array}{c}\text { Total } \\
\text { ( Injury ) }\end{array}$} \\
\cline { 2 - 8 } & LAF & HAF & LAF & HAF & UL & LL \\
& $(18)$ & $(19)$ & $(23)$ & $(30)$ & $(37)$ & $(53)$ \\
\hline N & 16 & 17 & 22 & 30 & 33 & 52 \\
Means & 1.12 & 1.11 & 1.04 & 1.26 & 1.12 & 1.01 \\
S.Ds. & 0.48 & 0.47 & 0.20 & 0.62 & 0.45 & 0.28 \\
t-ratio & \multicolumn{2}{c}{0.06 NS } & \multicolumn{2}{c}{1.83 NS } & 0.60 NS \\
NS = Not Significant & \multicolumn{4}{c}{}
\end{tabular}

Table 6 gives the statistical comparison of incidence of injuries recorded in the low and the high level achievement footballers with respect to Lower and Upper Limbs. No significant differences were observed in the occurrence of injuries between the low and the high level achievement footballers with respect to the lower and upper limbs.

\begin{tabular}{|c|c|c|c|c|c|}
\hline Cause of Injury & Achievement & $\mathbf{N}$ & Mean & SD & t-ratios \\
\hline \multirow{2}{*}{ Foul } & LAF & 06 & 0.24 & 0.57 & \multirow{2}{*}{$1.53 \mathrm{NS}$} \\
\hline & HAF & 19 & 0.70 & 0.87 & \\
\hline \multirow{2}{*}{ Tackle } & LAF & 03 & 0.08 & 0.27 & \multirow{2}{*}{$0.41 \mathrm{NS}$} \\
\hline & HAF & 06 & 0.15 & 0.35 & \\
\hline \multirow{2}{*}{ Stumble } & LAF & 10 & 0.29 & 0.51 & \multirow{2}{*}{$1.00 \mathrm{NS}$} \\
\hline & HAF & 03 & 0.07 & 0.26 & \\
\hline \multirow{2}{*}{ Collision } & LAF & 09 & 0.24 & 0.25 & \multirow{2}{*}{$1.11 \mathrm{NS}$} \\
\hline & HAF & 02 & 0.05 & 0.21 & \\
\hline \multirow{2}{*}{ Running } & LAF & 06 & 0.16 & 0.36 & \multirow{2}{*}{$0.28 \mathrm{NS}$} \\
\hline & HAF & 04 & 0.10 & 0.30 & \\
\hline \multirow{2}{*}{ Kicking the ball } & LAF & 01 & 0.02 & 0.16 & \multirow{2}{*}{0.14 NS } \\
\hline & HAF & 02 & 0.05 & 0.21 & \\
\hline \multirow{2}{*}{ Contact the ball } & LAF & 02 & 0.05 & 0.21 & \multirow{2}{*}{$0.29 \mathrm{NS}$} \\
\hline & HAF & 04 & 0.12 & 0.39 & \\
\hline
\end{tabular}

Ns $=$ Not significant.

Table 7 depicts the statistical comparison of incidence of injuries recorded in the low and the high level of achievement footballers with respect to the cause of injury. No significant differences were observed between the low and the high level of achievement footballers with respect to different causes like foul play $(\mathrm{t}=1.53)$, tackle $(\mathrm{t}=.41)$, 
stumble $(\mathrm{t}=1)$, collision $(\mathrm{t}=1.53)$, running $(\mathrm{t}=.28)$, kicking the ball $(\mathrm{t}=.14)$ and the ball contact $(\mathrm{t}=.29)$.

Table-8: Statistical comparison of incidence of injuries recorded in low and high level of achievement footballers with respect to the nature of injury.

\begin{tabular}{llcccc}
\hline Nature of injury & Achv & No. & Mean & S.D. & t-ratios \\
\hline \multirow{2}{*}{ Muscle } & LAF & 14 & 0.45 & 0.70 & \multirow{2}{*}{0.32 NS } \\
& HAF & 09 & 0.35 & 0.75 & \\
\hline \multirow{2}{*}{ Ligament } & LAF & 11 & 0.29 & 0.45 & \multirow{2}{*}{2.55 NS } \\
& HAF & 23 & 0.8 & 0.73 & \\
\hline \multirow{2}{*}{ Tendon } & LAF & 5 & 0.13 & 0.33 & \multirow{2}{*}{0.02 NS } \\
& HAF & 5 & 0.12 & 0.34 & \\
\hline \multirow{2}{*}{ Fracture } & LAF & 3 & 0.08 & 0.27 & \multirow{2}{*}{0.21 NS } \\
& HAF & 6 & 0.15 & 0.35 & \\
\hline \multirow{2}{*}{ TOTAL : } & LAF & 33 & 0.23 & 0.37 & \multirow{2}{*}{0.97 NS } \\
& HAF & 43 & 0.35 & 0.44 & \\
\hline NS =Not Significant & & & & &
\end{tabular}

Table 8 compares the incidence of injuries in the low and the high level of achievement footballers with respect to the nature of injury. Results indicate that no significant differences in nature of injury are found when comparison is made between the low and the high level of achievement footballers.

\section{Discussion:}

This study reveals that the high level achievement footballers suffered more injuries as compared to low level achievement footballers. This may be due to the fact that high level achievement footballers spend more time in training and competition. Increased occurrence of injuries in the high level achievement footballers may also be attributed to their increased intensity of the competitive temperament. While considering occurrence of injuries to the footballers belonging to the different field positions, significant differences of injuries were found. The results clearly indicate that those players directly involved in attack or defence are the ones most likely to be injured in this regard, most of the injuries were sustained by the center halves and center forward. With regard to the occurrence of injuries during training and competiton, a significant difference of injuries were found from the combined sample, the high level of achievement footballers was found to have got more injuries as compared to the low level achievement footballers. The relatively high incidence of injuries during training was probably due to the bad technique, low fitness and large amount of over training by the high level of achievement footballers. Zelisko et al (1982), Ekstrand et al (1983) and Maughan \& Miller (1983) also reported training related injuries in footballers, basketballers and marathon runners and ascribed them to the wrong techniques and poor fitness level of athletes. While comparing the occurrence of injuries between lower and upper limbs, no signifancant differences of injuries were found between the low and the high level of achievement footballers. With respect to the causes of injuries, no significant differences were found in the combined sample. No significant difference between the low and the high level of achievement footballers was found with regard to nature of injury. Similarly comparison of the occurence of injuries with respect to location, revealed no significant difference in the combined sample in the case of hamstring, however, significant injury differences were found in ankle $(\mathrm{t}$ $=3.53, \mathrm{P}<.01)$, shoulder $(\mathrm{t}=5.5, \mathrm{P}$ $<.001)$, and knee $(\mathrm{t}=2.37, \mathrm{P}<.05)$.

\section{Conclusion}

Within the limitations of the study, the results provide a useful insight into the cause, nature, location and 
outcome of injuries in football at the highest level. It is the first study in India to examine injuries to footballers having low and high level of achievement. This can provide a platform for further research in the area.

Acknowledgement

$$
\text { We are immensely }
$$

indebted to the organising committee and the players of the All India Mayor trophy footabll tournament who spared much of their valuable time and provided all the possible help whenever required by the investigator. The success of the pilot study was largely due to the high degree of cooperation and assistance received from the football players and coaches. The investigator is very grateful to them. Finally, thanks to all those who helped directly or indirectly in the completion of this pilot study.

\section{References}

Cromwell, F.J. and Gromely, W. 2000. A Pilot Study examining injuries in elite Gaelic footballers. Brit. J. Sports Medicine, 34: 104-108.
Ekstrand, J., Gillquist, J., Moller, M., Oberg, B. and Liljedahl, S.-O. 1983. Incidence of soccer injuries and their relation to training and team success Am. $J$. Sports Medicine, 11(2): 63-67.

Griffith, Winter, H. 1989. Complete guide to sports injuries. Motropolitan Book Co. (P).

Junge, A. 2004. Football injury during world cup 2002. Am. J. Sports Med., 32: 23S-27.

Maughan, R. J., Miller, T.D.B. 1983. Incidence of training related injuries among marathon runners, Brit. J. Sports Medicine, 17(3): 162-165.

Orchard, J. et al. 1997. Australian Football league injury report 1996. Football Record, 86: 14S-23 S.

Orchard, J. et al. 1998. Australian Football league injury report 1997. Football Record, 87(6): 54-61.

Pardon, E.T. 1997. Lower extermities are site of most soccer injuries, Phys. Sports Medicine, 5(6): 43-48.

Saxby, T. 1989. Turf toe "Abstract from the football Australian Conferences” J. Sci. Med. Sports, 2(1): 36.

Seward, H.G., Patrik, J.A. 1992. Three year survey of Victorian football league injuries. Med. Sports, 24 (2): $51-54$

Singh, S. K. \& Pagare, S.B. 2007. A Pilot Study Examining injuries in relation to field postion of competitive football players. National level seminar on Management of Physical Education and Sports: Benifits \& Challenges, M.C.C. Mumbai.

Singh, S. K. 2004. A study of injuries prevalence in Aquatic players. A published master thesis. Banaras Hindu University, Varanasi.

Singh, S. K. 2006. Injury prevalence in competitive swimmers. Indian Journal of Sports Study, 6: 40-44.

Waston A.W.S. 1993. Incidence and nature of sports injuries in Ireland. Am. J. Sports Med.; 21(1): $137-$ 143.

Zelisko, J, A. Noble, H. B. and Porter, M. A. 1982. Comparison of Men's and Women's professional basketball injuries. Am. J. Sports Med., 10(5): 297 